Check for updates

Cite this: J. Mater. Chem. B, 2020, 8, 1456

Received 23rd August 2019,

Accepted 7th January 2020

DOI: $10.1039 / c 9 t b 01805 k$

rsc.li/materials-b

\section{Effect of boron incorporation on the bioactivity, structure, and mechanical properties of ordered mesoporous bioactive glasses $\dagger$}

\author{
Leonie Deilmann, ${ }^{a}$ Oliver Winter, ${ }^{a}$ Bianca Cerrutti, ${ }^{\mathrm{b}}$ Henrik Bradtmüller, ${ }^{\mathrm{b}}$ \\ Christopher Herzig, ${ }^{c}$ Andreas Limbeck, (D) ${ }^{c}$ Olaf Lahayne, ${ }^{d}$ Christian Hellmich, ${ }^{d}$ \\ Hellmut Eckert (D) ${ }^{\text {be }}$ and Dominik Eder (D)*a
}

\begin{abstract}
$\mathrm{B}_{2} \mathrm{O}_{3}$ doped (0.5-15 mol\%) ordered mesoporous bioactive glasses (MBG) with the composition $80 \%$ $\mathrm{SiO}_{2}-15 \% \mathrm{CaO}-5 \% \quad \mathrm{P}_{2} \mathrm{O}_{5}$ were synthesized via a sol-gel based evaporation-induced self-assembly process using the block-copolymer P123 as a structure directing agent and characterized by biokinetic, mechanical and structural investigations. Nitrogen physisorption isotherms and electron microscopy indicate no detrimental effect of $\mathrm{B}_{2} \mathrm{O}_{3}$ on the ordered hexagonal pore structure. Boron incorporation increases both the bulk modulus and hardness of the glasses. In vitro bioactivity tests reveal a rapid initial release of $\mathrm{Ca}^{2+}$ and $\mathrm{PO}_{4}{ }^{3-}$ ions, followed by formation of hydroxyapatite carbonate within a few hours. Contrary to the tight incorporation of $\mathrm{Al}$ in $\mathrm{Al}$-doped MBGs, the rapid release of borate species into simulated-body-fluid suggests loosely bound species localized at the internal surfaces of the mesopores. ${ }^{29} \mathrm{Si},{ }^{11} \mathrm{~B},{ }^{31} \mathrm{P}$, and ${ }^{1} \mathrm{H}$ solid state NMR spectroscopy reveal that the majority of the borate is present as anionic $\mathrm{BO}_{4 / 2}{ }^{-}$species. The need for charge compensation leads to an increase in the average degree of polymerization of the phosphate species for high boron contents. ${ }^{11} \mathrm{~B}\left\{{ }^{31} \mathrm{P}\right\}$ rotational echo double resonance NMR results reveal the absence of $\mathrm{B}-\mathrm{O}-\mathrm{P}$ linkages. This structural model explains the rapid release of borate and the enhanced dissolution kinetics of the $\mathrm{Ca}^{2+}$ and phosphate species.
\end{abstract}

\section{Introduction}

In the late 1960s, Hench et al. introduced Bioglass ${ }^{\circledR}$ as a new class of biocompatible materials. ${ }^{1}$ Contact with human blood plasma or simulated body fluid $(\mathrm{SBF})$ readily creates a connective layer between the inorganic surface and the soft and/or hard tissue. This layer is typically made of crystalline hydroxyapatite, which is the main component of the inorganic part of bone. $^{2}$ Bioactive glasses are a later addition to this materials class and considered next-generation. According to Cao and Hench, ${ }^{3}$ they are Class A biomaterials that show both osteoconductive and osteoproductive behavior as well as an enhanced bone proliferation.

\footnotetext{
${ }^{a}$ Institut für Materialchemie, Technische Universität Wien, Getreidemarkt 9/BC/02, 1060 Wien, Austria. E-mail: dominik.eder@tuwien.ac.at

${ }^{b}$ Instituto de Física de Sao Carlos, Universidade de Sao Paulo, CEP 369, Sao Carlos SP 13566-590, Brazil

${ }^{c}$ Institut für Chemische Technologien und Analytik, Technische Universität Wien, Getreidemarkt 9/164, 1060 Wien, Austria

${ }^{d}$ Institut für Mechanik der Materialien und Strukturen (IMWS),

Technische Universität Wien, Karlsplatz 13/202, 1040 Wien, Austria

${ }^{e}$ Institut für Physikalische Chemie, WWU Münster, Corrensstr. 28/30,

48149 Münster, Germany. E-mail: eckerth@uni-muenster.de

$\dagger$ Electronic supplementary information (ESI) available. See DOI: 10.1039/c9tb01805k
}

The ability to directly bond to bone without the danger of an inflammatory response renders these materials promising candidates for bone tissue engineering.

The most common Bioglass ${ }^{\circledR}, 45 \mathrm{~S} 5$, has a composition of $45 \% \mathrm{SiO}_{2}, 24.5 \% \mathrm{Na}_{2} \mathrm{O}, 24.5 \% \mathrm{CaO}$ and $6 \% \mathrm{P}_{2} \mathrm{O}_{5}$ (wt\%) and was first produced in 1971 by Hench et al. via the melt-quenching method. ${ }^{2}$ The sol-gel derived bioactive glass was introduced 20 years later by Li et al. ${ }^{4}$ Sol-gel glasses offer many advantages, including a larger surface area due to inherent porosity, which can significantly increase the number of binding sites and hence the bioactivity. In addition, sol-gel glasses offer lower synthesis and processing temperatures and often exhibit higher purity and homogeneity. Furthermore, $\mathrm{Na}_{2} \mathrm{O}$ can be eliminated from the glass system, and the compositional range can be expanded up to silica-rich compositions.

In 2004 Yan $e t ~ a l . ~{ }^{5}$ introduced hexagonally ordered mesopores into bioactive sol-gel glasses by using block-copolymers as structure directing agents in combination with the evaporationinduced self-assembly (EISA) process. ${ }^{6}$ In short, the inorganic precursors for the oxide components in the glass system (e.g. tetraethyl orthosilicate, TEOS, for $\mathrm{SiO}_{2}$ ) and a block-copolymer (e.g. the commercially available Pluronics ${ }^{\mathbb{B}}$ P123) are mixed into a solvent at c $<\mathrm{cmc}$ (critical micelle concentration). Upon evaporation 
of the solvent the surfactant concentration increases beyond cmc, which initiates spontaneous organization through noncovalent interactions and micelle formation at the mesoscale. Concurrently with the self-assembly process, hydrolysis and condensation reactions of the precursors lead to the formation of amorphous pore walls that separate the mesopores. The arrangement of the pores depends on various synthesis conditions, such as choice of polymer, temperature, $\mathrm{pH}$, and reactant ratios. $^{7,8}$ So far, mesoporous glasses with twodimensional (2D) hexagonal or three-dimensional (3D) cubic pore structures have been obtained. ${ }^{5,9}$

Due to their tunable porosity and large surface area, mesoporous bioactive glasses (MBGs) are ideal for various applications in biomaterials science. They can be filled either with pharmaceuticals for drug delivery or in vivo with osteogenetic cells/proteins for bone tissue engineering. ${ }^{10}$ Above all, MBG are ideal candidates for bone tissue regeneration, because they show a much faster and more intense hydroxycarbonate apatite (HCA) formation compared to the traditional sol-gel or meltquenched glasses. ${ }^{5}$ However, the low mechanical strength of MBG still poses a major challenge in applications. ${ }^{11,12}$ To alter the structural and textural properties, additional ions or oxides can be incorporated into the basic $\mathrm{SiO}_{2}-\mathrm{CaO}-\mathrm{P}_{2} \mathrm{O}_{5}$-system of the bioactive glass.

One potential candidate to strengthen the mechanical properties of $\mathrm{MBG}$ is $\mathrm{B}_{2} \mathrm{O}_{3}$ due to the abrasion resistance and hardness that it imparts upon silicate and phosphate glasses; hence it has been introduced as an additional component into melt-derived glasses. ${ }^{13}$ Boron doped bioactive glasses are currently attracting interest also owing to their improved biocompatibility and antibacterial function. ${ }^{14,15}$ Boron can influence vital processes, including embryogenesis, bone growth and psychomotor skills. ${ }^{16,17}$ Additionally, it has been recognized to preserve bone health, and a diet containing adequate amounts of boric acid enhances bone strength under compression. ${ }^{16,18}$ It is also an essential mineral in the conversion of vitamin $\mathrm{D}$ to its active form. Moreover, boron-containing bioglass has demonstrated increased proliferation of osteoblasts in cell cultures, ${ }^{16,17,19}$ and the controlled release of boron from bioglass can favor the regeneration of bone tissues. So far, however, there has been no comprehensive study that correlated the structural information of boron incorporation in MBGs with their mechanical properties and bioactive response.

In this work we doped MBG of the system $\mathrm{SiO}_{2}-\mathrm{CaO}-\mathrm{P}_{2} \mathrm{O}_{5}$, (80-x:15:5 mol\%) with different amounts of boron trioxide ranging from $x=0.5$ to $15 \mathrm{~mol} \%$. We thoroughly analyzed the textural properties of MBG, such as pore geometry, porosity and surface area. Moreover, we performed in vitro bioactivity tests and nanoindentation studies and correlated the changes in bioactivity and mechanical properties with the changes in glass structure revealed by in-depth solid-state nuclear magnetic resonance (NMR) spectroscopic studies. While solid state NMR has been widely used for the structural characterization of bioglasses, ${ }^{20}$ to date the literature on boron-containing systems is rather limited. Work by the Eden group stands out, in particular reporting detailed compositional dependences and advanced connectivity information on the basis of twodimensional dipolar NMR spectroscopy in traditional meltquenched bioglasses. ${ }^{21,22}$ To date, however, no experimental data on boron-containing MBGs are available. In the present contribution we develop a quantitative structural description of these materials based on a comprehensive solid-state NMR investigation, providing a suitable structural rationale for the composition-property relationship.

\section{Materials and methods}

\section{Sample preparation}

MBGs with glass compositions of $80-x \mathrm{~mol} \% \mathrm{SiO}_{2}, 15 \mathrm{~mol} \%$ $\mathrm{CaO}, 5 \mathrm{~mol} \% \mathrm{P}_{2} \mathrm{O}_{5}$, and $x=0-15 \mathrm{~mol} \% \mathrm{~B}_{2} \mathrm{O}_{3}$ were prepared according to the synthesis reported by Yan et al., ${ }^{5}$ using commercial Pluronic $^{\circledR}$ block-copolymers as structure-directing agents. The corresponding glass compositions are listed in Table 1. The overall experimental procedure is analogous to that previously used by us to obtain $\mathrm{Al}_{2} \mathrm{O}_{3}$-doped $\mathrm{MBGs}^{23}$ and the details are summarized in ESI. $\dagger$

In short, Pluronic ${ }^{\circledR} \mathrm{P} 123\left(2 \mathrm{~g}, M_{\mathrm{w}}=5800\right.$, BASF $)$ was dissolved in ethanol $(38 \mathrm{~mL})$ under magnetic stirring followed by the addition of the respective amounts of the precursors. The precursors were added in the following sequence and each precursor was completely dissolved before the addition of the next one. Tetraethyl orthosilicate (TEOS, 99\% ABCR), calcium nitrate tetrahydrate $\left(\mathrm{Ca}\left(\mathrm{NO}_{3}\right)_{2} \times 4 \mathrm{H}_{2} \mathrm{O}, 99 \% \mathrm{ACS}\right)$, triethyl phosphate (TEP, 99\% Merck), and boric acid $\left(\mathrm{H}_{3} \mathrm{BO}_{3}, 99 \%\right.$, ABCR) were used as precursors for $\mathrm{SiO}_{2}, \mathrm{CaO}, \mathrm{P}_{2} \mathrm{O}_{5}$, and $\mathrm{B}_{2} \mathrm{O}_{3}$, respectively. Hydrochloric acid $(0.5 \mathrm{~mL}, 0.5 \mathrm{M})$ was added to catalyze the hydrolysis reaction. The final solution was stirred at room temperature (RT) for $24 \mathrm{~h}$, then transferred into a Petri dish and stored at RT for 6 days to initiate the EISA process. The resulting gels were dried and calcined in a muffle oven at $600{ }^{\circ} \mathrm{C}$ for $2 \mathrm{~h}$ (heating/cooling rate $1{ }^{\circ} \mathrm{C} \mathrm{min}^{-1}$ ) to remove the polymer.

\section{Materials characterization}

The structure of the bioactive glasses was characterized by high resolution transmission electron microscopy (HRTEM), using a Libra 200 microscope (Carl Zeiss Microscopy $\mathrm{GmbH}$ ), as well as Tecnai G20 and F20 (FEI Tecnai ${ }^{\mathrm{TM}}$ ), all operated with an acceleration voltage of $200 \mathrm{keV}$. The powders were dispersed in ethanol by ultrasonication and drop-casted on a copper 200 mesh Lacey carbon coated grid (Plano).

Table 1 Nominal glass compositions of $\mathrm{B}_{2} \mathrm{O}_{3}$ doped MBGs

\begin{tabular}{llllc}
\hline & \multicolumn{4}{l}{ Composition in mol\% } \\
\cline { 2 - 5 } Sample & $\mathrm{SiO}_{2}$ & $\mathrm{CaO}$ & $\mathrm{P}_{2} \mathrm{O}_{5}$ & $\mathrm{~B}_{2} \mathrm{O}_{3}$ \\
\hline MBG & 80 & 15 & 5 & 0 \\
0.5 B-MBG & 79.5 & 15 & 5 & 0.5 \\
1.0 B-MBG & 79 & 15 & 5 & 1 \\
3.0 B-MBG & 77 & 15 & 5 & 3 \\
5.0 B-MBG & 75 & 15 & 5 & 5 \\
10.0 B-MBG & 70 & 15 & 5 & 10 \\
15.0 B-MBG & 65 & 15 & 5 & 15
\end{tabular}


Surface area and pore size distribution were analyzed by $\mathrm{N}_{2}$ physisorption (ASAP 2010 Micromeritics $\mathrm{GmbH}$ ), using the Brunauer-Emmett-Teller (BET) and Barret-Joyner-Halenda $(\mathrm{BJH})$ method, ${ }^{24}$ respectively. To remove moisture and adsorbed gases the samples were heated at temperatures up to $150{ }^{\circ} \mathrm{C}$ under vacuum for several hours.

\section{Mechanical properties}

Elasticity modulus and hardness were measured by the nanoindentation method, following the procedure of Oliver and Pharr. $^{25}$ A TI-900 TriboIndenter ${ }^{\circledR}$ (Hysitron Incorporated, Minneapolis, USA) was used. The diamond tip had the Berkovich geometry with half angle of $65.27^{\circ}$, included angle of $142.30^{\circ}$, Young's modulus of $1140 \mathrm{GPa}$ and Poisson's ratio of 0.07 . The tip diameter was $50 \mathrm{~nm}$. Each sample was measured in the quasi-static mode which is a standard measuring option for all indentation tests. Small pieces of calcined glass were glued on a silicon wafer on a standard sample holder that is usually used for SEM. This sample holder was placed onto the magnetic nanoindenter sample stage and samples were investigated with a pre-defined measuring program. 225 unique single indents on a $15 \times 15$ grid and with $20 \mu \mathrm{m}$ distance between the single indents were taken for every sample, resulting in an area of $300 \times 300 \mu \mathrm{m}$ in size. The load function or maximum force was increased from 1000 to $12000 \mu \mathrm{N}$ in steps of $53.125 \mu \mathrm{N}$ to obtain load $v$. displacement curves.

\section{In vitro bioactivity tests}

A simulated body fluid (SBF) solution was prepared according to Kokubo et al. ${ }^{26}$ The bioactive glass samples (40 mg) were soaked in SBF $(40 \mathrm{~mL})$ at $36.5{ }^{\circ} \mathrm{C}$ for time periods between $10 \mathrm{~min}$ to 7 days and subsequently filtrated and dried in order to terminate the formation of hydroxycarbonate apatite (HCA). The ratio of bioactive glass to SBF was $1 \mathrm{mg} \mathrm{mL}^{-1}$.

The concentrations of the solute species (calcium, phosphorus, silicon, and boron) were measured in regular time intervals by inductively coupled plasma emission spectroscopy (ICP-OES). Prior to analysis samples were diluted $(1: 10)$ with $1 \%(\mathrm{v} / \mathrm{v})$ nitric acid and indium was added as internal standard with a final concentration of $1 \mu \mathrm{g} \mathrm{mL} \mathrm{m}^{-1}$. Matrix matched standard solutions required for external calibration were prepared just before use by appropriate combination of single element standards (Carl ROTH $^{\mathbb{B}}$ Single-Element ICP-Standard-Solution Roti ${ }^{\circledR}$ Star) with 1:10 diluted SBF, followed by the addition of the internal standard. Samples and standards were analyzed with an iCAP 6500 ICP-OES spectrometer (Thermo Scientific, USA) equipped with Mira Mist nebulizer (Burgener Research Inc., Ontario, Canada) and a Teflon cyclonic spray chamber to keep Si background as low as possible. Sample-uptake was achieved with the peristaltic pump of the instrument. Background-corrected emission signals were recorded in the radial viewing mode and processed using Qtegra software (Thermo Scientific, USA). Four replicates with an integration time of $5 \mathrm{~s}$ each were measured for samples as well as standard solutions. The optimized ICP parameters are summarized in Table S1 (ESI $\dagger$ ). Observed signal intensities were normalized using the signal response for the internal standard (In), and finally converted into concentration units by means of external aqueous calibration. Derived In signals were constant over each measurement session (less than 5\% relative standard deviation for the whole measurement period, indicating the absence of temporal trends), and no significant difference in In-response between samples and calibration standards was observed.

Mineralization of HCA of the identical samples was monitored by X-ray powder diffraction (XRD), using a Bruker ASX D8 diffractometer, equipped with a $\mathrm{Cu}-\mathrm{K} \alpha$ source. Detected scattering angles ranged from $20^{\circ}$ to $80^{\circ}$.

\section{Solid state NMR studies}

Solid state NMR experiments were performed on 5.7 T Varian/ Agilent 240-MR DD2 and 14.1 T Bruker Advance Neo spectrometer systems. The spectrometers were equipped with a $4 \mathrm{~mm}$ double resonance probe (Agilent) and a $2.5 \mathrm{~mm}$ triple resonance probe (Bruker). ${ }^{29} \mathrm{Si}$ MAS-NMR spectra were obtained on the $5.7 \mathrm{~T}$ magnet using the following conditions: $90^{\circ}$ pulses near $5.0 \mu$ s at spinning speeds near $5.0 \mathrm{kHz}$, and a relaxation delay of $180 \mathrm{~s}$. Spectra were deconvoluted into various GaussLorentz components using the DMFIT software ${ }^{27}$ and referenced to tetramethylsilane using solid tetrakis (trimethylsilyl) silane as a secondary reference. ${ }^{31} \mathrm{P}$ MAS-NMR spectra were recorded at $5.7 \mathrm{~T}$, using $90^{\circ}$ pulses near $5.0 \mu \mathrm{s}$, at spinning speeds in the range of $12.0 \mathrm{kHz}$, and relaxation delays up to $1200 \mathrm{~s}$. Chemical shifts are reported relative to an $85 \% \mathrm{H}_{3} \mathrm{PO}_{4}$ solution. ${ }^{1} \mathrm{H}$ MAS-NMR spectra were measured at $600 \mathrm{MHz}$, with a sample spinning speed of $25.0 \mathrm{kHz} .{ }^{11} \mathrm{~B}$ MAS-NMR spectra were recorded at both 5.7 and 14.1 $\mathrm{T}$ using short pulses $\left(<30^{\circ}\right)$ of $0.5 \mu$ s length and a relaxation delay of $5 \mathrm{~s}$. Chemical shifts are reported relative to a $\mathrm{BF}_{3} \cdot \mathrm{OEt}_{2}$ solution, using solid $\mathrm{BPO}_{4}(-3.5 \mathrm{ppm})$ as a secondary standard. Spectra were simulated using the DMFIT program, with two Gaussian components for the $\mathrm{B}^{(4)}$ and a second-order quadrupolar line shape for the $\mathrm{B}^{(3)}$ species. ${ }^{11} \mathrm{~B}\left\{{ }^{31} \mathrm{P}\right\}$ rotational echo double resonance (REDOR) measurements ${ }^{28}$ were conducted at $14.1 \mathrm{~T}$ with a rotor spinning frequency of $15.0 \mathrm{kHz}$. Solid ${ }^{11} \mathrm{~B} 180^{\circ}$ pulse lengths were typically $2.8 \mu$ s for measurements observing threecoordinate boron and $5.3 \mu$ s for measurements observing fourcoordinate boron. ${ }^{31} \mathrm{P}$ recoupling $\pi$ pulses were consistently employed with a length of $3 \mu \mathrm{s}$. Recycle delays were between $1 \mathrm{~s}$ and 2 s, followed by a pre-saturation train of $20 \pi / 2$ pulses. The normalized signal attenuation data obtained with the initial decay regime $\left(\Delta S / S_{0} \leq 0.2\right)$ as a function of dipolar evolution time $\left(N T_{\mathrm{r}}=\right.$ number of rotor cycles times rotor period $)$ were fitted to a parabola according to the expression ${ }^{29}$

$$
\Delta S / S_{0}=\left(4 / 3 \pi^{2}\right)\left(N T_{\mathrm{r}}\right)^{2} M_{2(\mathrm{~B}-\mathrm{P})}
$$

Here $M_{2(\mathrm{~B}-\mathrm{P})}$ is the dipolar second moment characterizing the mean squared average of the ${ }^{11} \mathrm{~B}^{-}{ }^{31} \mathrm{P}$ magnetic dipole-dipole coupling constant, which can be related to internuclear distance distributions using van Vleck theory. ${ }^{30}$ Conditions for the ${ }^{31} \mathrm{P}\left\{{ }^{11} \mathrm{~B}\right\}$ rotational echo adiabatic passage double resonance (REAPDOR) experiments were similar as in the REDOR experiments and the length of the ${ }^{11} \mathrm{~B}$ adiabatic pulse was set to one third of the rotor period $(22.22 \mu \mathrm{s})$ using a ${ }^{11} \mathrm{~B}$ nutation 
frequency of $60 \mathrm{kHz}$. Recycle delays were limited to $800 \mathrm{~s}$, and a pre-saturation train of $20 \pi / 2$ pulses was used.

\section{Results}

\section{Textural characterization}

XRD confirms the amorphous nature of all glasses and the absence of any crystalline impurities, although the presence of nanosized species below the detection limit cannot be excluded (ESI, $\dagger$ Fig. S1).

Typical TEM images of the samples are shown in Fig. 1 and reveal that all the samples consist of well-ordered mesopores with $2 \mathrm{D}$ hexagonal pore arrangement with average pore diameters of around $5 \mathrm{~nm}$. There was no noteworthy effect of the incorporation of boron on the pore architecture or ordering (Fig. S2 and S3, ESI $\dagger$ ).

The nitrogen adsorption-desorption isotherms in Fig. 1c show for all samples type IVa isotherms with H1 hysteresis, which is typical for mesoporous materials with uniform pores and narrow pore size distributions. ${ }^{24}$ The BJH analysis further confirms the narrow pore size distributions with maxima between 4-6 nm, in good agreement with the TEM results. In contrast to the pore characteristics, the boron incorporation has a considerable impact on the BET specific surface areas (see Fig. 1d). Remarkably, already the addition of $1 \mathrm{~mol} \% \mathrm{~B}_{2} \mathrm{O}_{3}$ results in a strong decrease of the surface area by about $20 \%\left(461 \mathrm{~m}^{2} \mathrm{~g}^{-1}\right)$ compared to the pure MBG $\left(556 \mathrm{~m}^{2} \mathrm{~g}^{-1}\right)$. The surface area continues to decrease with increasing $\mathrm{B}_{2} \mathrm{O}_{3}$ content, albeit to a lower extent. The addition of 10 and $15 \mathrm{~mol} \% \mathrm{~B}_{2} \mathrm{O}_{3}$ further leads to a significant loss in surface area from 417 to $343 \mathrm{~m}^{2} \mathrm{~g}^{-1}$.

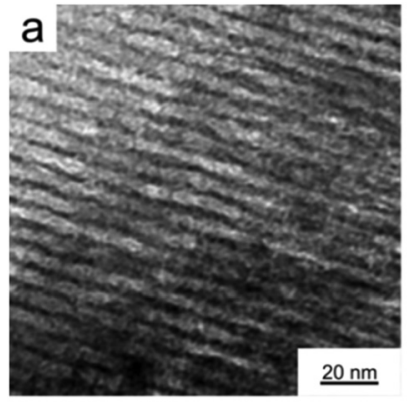

C

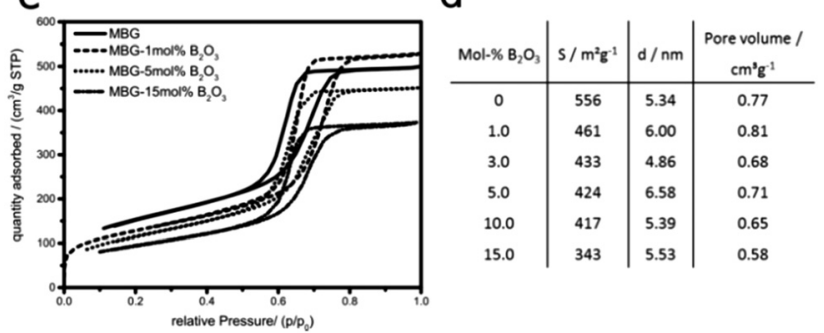

Fig. 1 TEM images of boron-doped MBGs with concentrations of (a) 0.5 and (b) 15 mol\% $\mathrm{B}_{2} \mathrm{O}_{3}$, showing 2D hexagonally-ordered mesopores, (c) nitrogen adsorption-desorption isotherms from 0, 1, 5 and $15 \mathrm{~mol} \%$ $\mathrm{B}_{2} \mathrm{O}_{3}$-doped MBGs and (d) surface areas, average pore diameters and pore volumes extracted from $\mathrm{N}_{2}$ sorption data of $\mathrm{B}_{2} \mathrm{O}_{3}$-doped MBGs.
Considering that neither the size nor the arrangement of the mesopores is affected by the incorporation of $\mathrm{B}_{2} \mathrm{O}_{3}$; the decrease in surface area is likely associated with a partial collapse of micropores within the glass's walls or a pore blocking enacted by the presence of $\mathrm{B}_{2} \mathrm{O}_{3}$.

\section{Mechanical properties}

Fig. 2 summarizes the bulk modulus and hardness data of the MBG samples obtained by nanoindentation. The maximum indentation forces implied indentation depths ranging from $35 \mathrm{~nm}$ to $4600 \mathrm{~nm}$. The indentation depths are separated by a factor of six from the size of the material phase inside the investigated material volume (representative volume element $\mathrm{RVE})^{31}$ and this phase size typically measures one third to one half of the size of the RVE. ${ }^{32}$ Hence, our indentations probe material volumes measuring one third to one half of the indentation depth, i.e. RVEs of $100 \mathrm{~nm}$ to $2300 \mathrm{~nm}$ size. Such RVEs obviously refer to the porous material encompassing several porous cells as seen in Fig. 1. Given a surface roughness of 10-30 nm, which is less than one fifth of the herein recorded indentation depths, ${ }^{33}$ the nanoindentation-probed surfaces can be regarded as sufficiently flat so as to allow for the employment of the classical Oliver-Pharr solution for the determination of hardness and elastic modulus. Corresponding sample-specific statistical distributions can be well fitted by means of one single Gaussian probability distribution function each; with expected values and standard deviations found in Fig. $2 b$. Thereby, deviations from the expected values may stem from deviations of patches of material with the textures seen in Fig. 1, from the loading direction of the indenter. Both, modulus and hardness increased considerably with the incorporation of increasing amounts of boron into MBG. The addition of $0.5 \mathrm{~mol} \%$ led to an increase of nearly 50\% compared with the pure MBG, while an additional $50 \%$ increase required the addition of $10 \%$ $\mathrm{B}_{2} \mathrm{O}_{3}$. Interestingly, the samples with $\mathrm{B}_{2} \mathrm{O}_{3}$ contents of $3 \%$ and larger exhibit modulus values comparable to that of cortical bone (16.6 to $21.2 \mathrm{GPa}){ }^{34}$ which make them suitable candidates for load-bearing applications.

\section{In vitro bioactivity studies}

All the samples were soaked in SBF for different times up to 7 days, filtered and the solute analyzed by ICP-OES. The data are summarized in Fig. 3 and Fig. S4 (ESI $\dagger$ ).

The temporal evolutions of the calcium (Fig. 3a) and phosphate ion concentrations (Fig. 3b) show the typical profile for bioactive glasses: an increase in concentration within the first 4 hours, followed by a considerable decrease upon re-uptake, due to the formation of Ca-phosphates (e.g. hydroxycarbonate apatite, HCA) on the samples' surfaces. The concentrations reached saturation levels after approximately one day. The phosphate release and uptake kinetics seem to be independent of the sample composition (Fig. 3b). In contrast, both release and re-uptake of $\mathrm{Ca}^{2+}$ ions varied with $\mathrm{B}_{2} \mathrm{O}_{3}$ concentration. Generally, it appears that high concentrations of boron facilitate the release of $\mathrm{Ca}^{2+}$ but suppress its re-uptake and the subsequent formation of HCA, e.g. residual concentration of $110 \mathrm{ppm}$ 
a

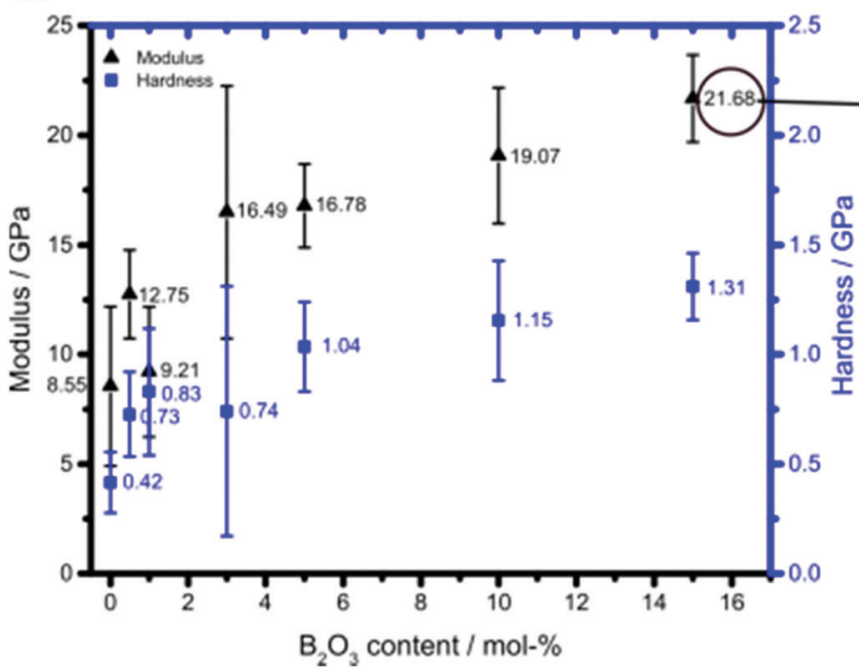

b

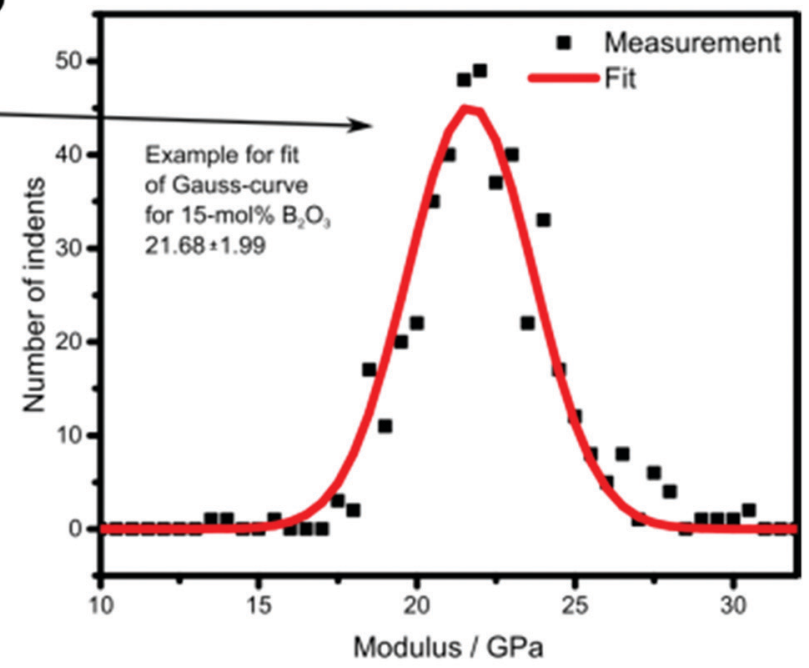

Fig. 2 (a) Dependence of modulus and hardness for $\mathrm{B}_{2} \mathrm{O}_{3}$-doped MBG on boron oxide content and (b) example for fit of $\mathrm{Gauss}$-curve for 15 mol\% $\mathrm{B}_{2} \mathrm{O}_{3}$.

a
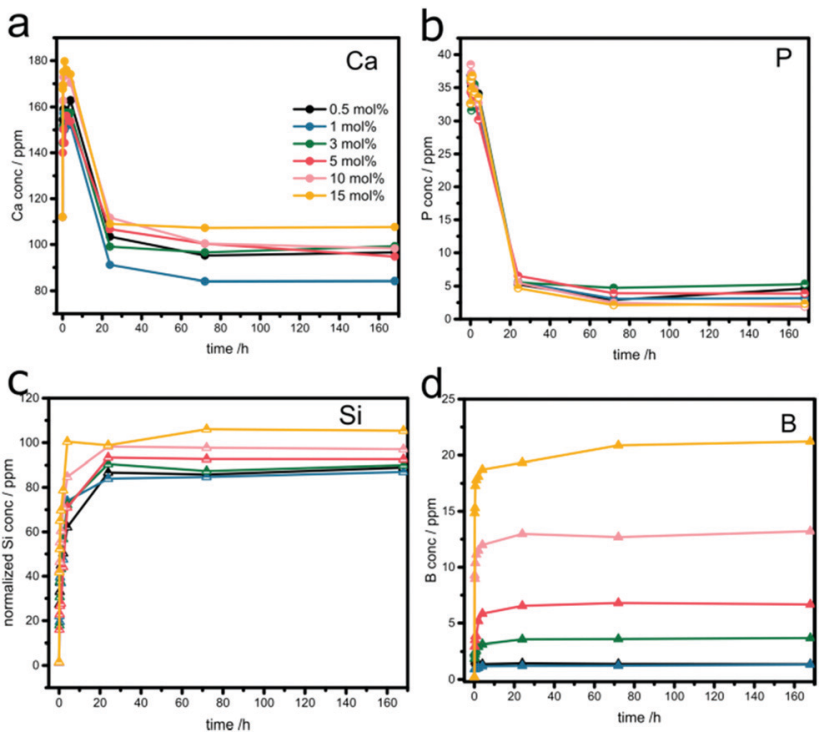

d

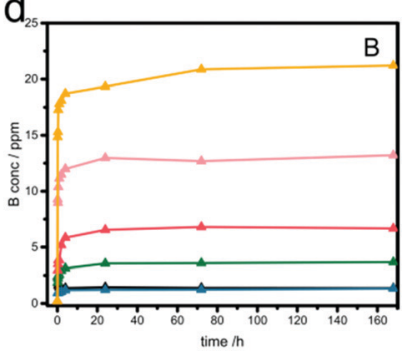

Fig. 3 Temporal evolutions of (a) Ca, (b) P, (c) normalized $\mathrm{Si}$, and (d) B concentrations in SBF after soaking boron-doped MBGs.

( $\mu \mathrm{g} \mathrm{mL}^{-1}$ ) for $15 \% \mathrm{~B}$. The best performance was found with $1 \% \mathrm{~B}$, which showed a moderate ion release, but the strongest uptake profile (residual concentration of $85 \mathrm{ppm}$ ).

Fig. 3c summarizes the Si release profiles, normalized to the initial Si content in the samples. In all samples, the majority of Si was released within the first few hours, reaching a saturation level of around $70 \mathrm{ppm}$ after one day. It is important to note than this final level is significantly lower than the maximum amount of Si present in the glasses, indicating that part of it remained in the sample, presumably blocked from dissolution by the HA layer formed on the surface. The relative amounts of released Si increase slightly with increasing boron concentration. For example, the percentage of released Si in the sample with

$15 \%$ B is about $24 \%$ higher than in the sample with $0.5 \%$ B. Furthermore, there is a significant effect of boron on the release kinetics of $\mathrm{Si}$. The initial rates, taken from the first 4 hours, increased from $\sim 5.2 \mathrm{ppm} \mathrm{h}^{-1}$ to $\sim 9 \mathrm{ppm} \mathrm{h}^{-1}$. Both results suggest that boron facilitates the release of Si from the glass network.

The boron release profiles, summarized in Fig. 3d, are similar for all samples. The majority of boron gets released within the first few hours before reaching saturation after one day. The concentrations in the solution correspond well with the respective glass composition, as seen in the linear increase in Fig. S4 (ESI $\dagger$ ). This suggests a complete boron release and indicates a "loose" incorporation, likely in the form of species attached on the interior surface.

The formation of crystalline HCA was confirmed by XRD (see Fig. S1, ESI $\dagger$ ). The characteristic (002), (211) and (222) reflections for HCA become visible at $2 \theta$ values of $25.8^{\circ}, 31.8^{\circ}$ and $46.7^{\circ}$, respectively, for all samples after 4 hours. Importantly, the $1 \%$ B sample shows the most prominent peaks, which is in line with the ICP studies.

\section{Structural characterization by solid-state NMR}

Fig. 4 summarizes the ${ }^{29} \mathrm{Si}$ MAS-NMR spectra and Table 2 specifies the line shape parameters of their deconvolution components. The spectrum of the B-free sample comprises three principal contributions: the dominant one near $-110 \mathrm{ppm}$ can be assigned to $\mathrm{Si}^{(4)}$ units, the shoulder near $-100 \mathrm{ppm}$ to some residual $\mathrm{Si}^{(3)} \mathrm{OH}$ groups and the weak feature near $-90 \mathrm{ppm}$ to a few $\mathrm{Si}^{(2)}(\mathrm{OH})_{2}$ units. While the intensities of these resonances are subject to some variations, they do not show a systematic dependence on $\mathrm{B}_{2} \mathrm{O}_{3}$ content. Note, however, that the $\mathrm{Si}^{(4)}$ component can be fitted to two distinct contributions near -108 and $-112 \mathrm{ppm}$. As the peak ratio for these two components is independent of borate content, the two components cannot be attributed to $\mathrm{Si}^{(4)}{ }_{\mathrm{OB}}$ and $\mathrm{Si}^{(4)}{ }_{1 \mathrm{~B}}$ species in a straightforward manner. 

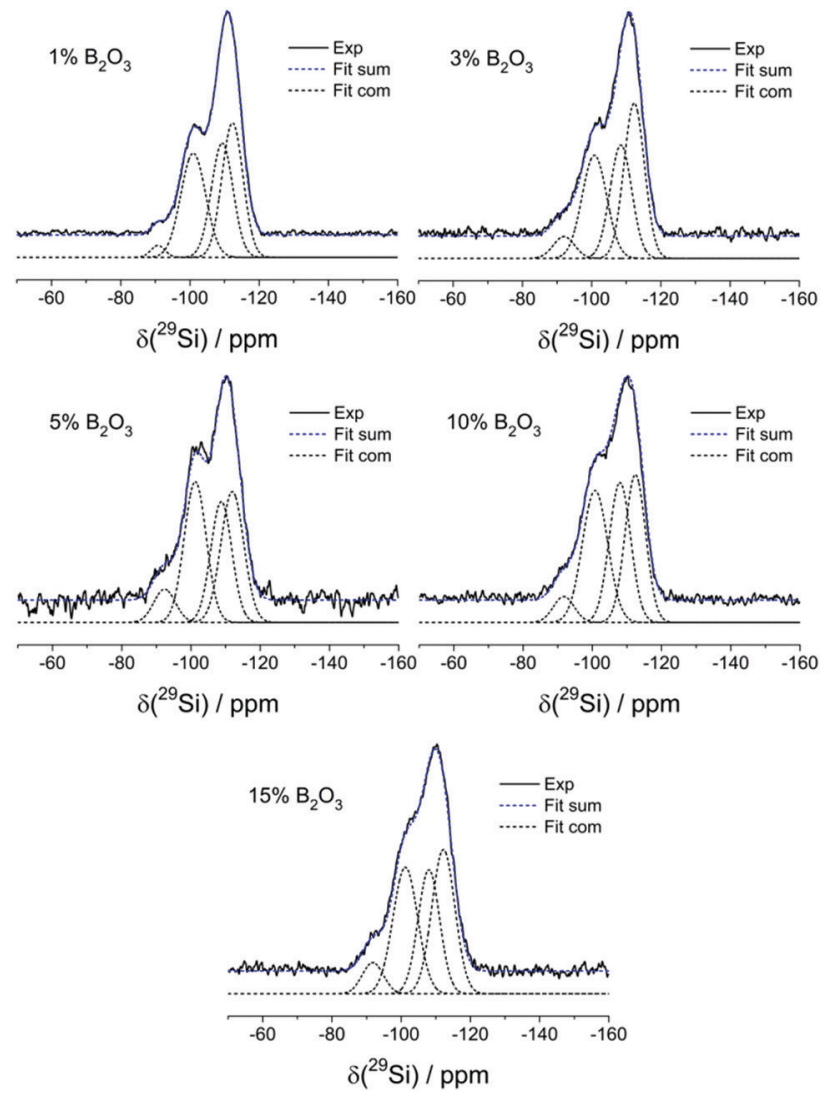

Fig. 4 Experimental and simulated ${ }^{29} \mathrm{Si}$ MAS-NMR spectra of $\mathrm{B}_{2} \mathrm{O}_{3}$ doped MBGs.

Table 2 Deconvolution parameters used in the simulation of the ${ }^{29} \mathrm{Si}$ MAS-NMR spectra of $\mathrm{B}_{2} \mathrm{O}_{3}$ doped MBGs

$\mathrm{mol} \%$

$\mathrm{B}_{2} \mathrm{O}_{3} \quad$ Component $\delta_{\text {iso }}^{\text {cs }} / \mathrm{ppm} \pm 0.5 \quad \mathrm{FWHM} / \mathrm{ppm} \pm 0.5$ Area $/ \% \pm 2 \%$

\begin{tabular}{rrrrr}
\hline 15 & 1 & -112.2 & 7.8 & 34 \\
& 2 & -108.0 & 7.3 & 27 \\
& 3 & -101.2 & 8.4 & 32 \\
& 4 & -91.8 & 7.1 & 7 \\
10 & 1 & & & \\
& 2 & -112.4 & 7.0 & 31 \\
& 3 & -108.0 & 7.3 & 30 \\
& 4 & -91.8 & 8.6 & 5 \\
& & & 7.1 & \\
5.0 & 1 & -112.0 & 7.8 & 27 \\
& 2 & -109.0 & 7.2 & 33 \\
& 3 & -101.2 & 7.5 & 8 \\
& 4 & -92.4 & 7.3 & 37 \\
3.0 & 1 & & & 28 \\
& 2 & -112.3 & 7.0 & 29 \\
& 3 & -108.5 & 7.4 & 6 \\
& 4 & -100.8 & 8.4 & 35 \\
1.0 & 1 & -92.0 & 7.2 & 31 \\
& 2 & & & 32 \\
& 3 & -112.3 & 7.2 & 2
\end{tabular}

Rather, the fitting of this $\mathrm{Si}^{(4)}$ spectral feature to two Gaussians should be considered an artificial approach to mimic the more realistic scenario that a continuous distribution of isotropic chemical shifts is present. The ${ }^{29} \mathrm{Si}$ spectra also give no indication of any low-frequency component, suggesting the absence of $\mathrm{Si}-\mathrm{O}-\mathrm{P}$ linkages. Overall, inspection of Table 2 reveals that the silicon speciation is more or less independent of the boron content. The data are most consistently interpreted in terms of a fully polymerized $\mathrm{Si}^{(4)}$ network with silanol defects. There is no evidence that the introduction of boron into these glasses (and the associated demand for cations to charge compensate anionic borate species) affects the connectivity of the silicate network. There is also no strong evidence for the incorporation of $\mathrm{B}^{(4)}$ units into the silicate framework from these data, even though some subtle changes in the overall appearance of the line shapes in the glasses with higher boron contents may point into this direction.

Fig. 5 shows the ${ }^{11} \mathrm{~B}$ MAS-NMR spectra of the present samples. All the glasses containing $5 \% \mathrm{~B}_{2} \mathrm{O}_{3}$ or less show slightly asymmetric Gaussian line shapes, as characterized by an isotropic chemical shift near $-1.1 \pm 0.5 \mathrm{ppm}$. Based on its chemical shift and the absence of a nuclear electric quadrupolar effect upon the line shape, we can assign this signal to fourcoordinated boron $\left(\mathrm{B}^{(4)}\right)$ species. To account for the asymmetry, two closely spaced Gaussian components are used in the fitting of the $\mathrm{B}^{(4)}$ spectral line shape for all the samples. In the two samples with the highest $\mathrm{B}_{2} \mathrm{O}_{3}$ contents (10 and $15 \mathrm{~mol} \%$ ), respectively, the $\mathrm{B}^{(4)}$ peak is substantially broader and its isotropic chemical shift moves towards $-0.5 \mathrm{ppm}$. In addition, there is clear evidence of another spectral component, whose line shape can be fitted to a spectrum influenced by quadrupolar interaction within the regime of second-order perturbation theory. The parameters, isotropic chemical shift, $\delta_{\text {iso }}^{\text {cs }}=19.0 \pm 0.5 \mathrm{ppm}$, nuclear electric quadrupolar coupling constant, $C_{\mathrm{Q}}=2.60 \pm 0.05 \mathrm{MHz}$, and electric field gradient asymmetry parameter, $\eta_{\mathrm{Q}}=0.35 \pm 0.05$ do not allow one to decide unambiguously whether this species is a symmetric $\mathrm{B}^{(3)}$ unit or an anionic three-coordinate borate species bound to a non-bridging oxygen, i.e. a $\mathrm{B}^{(2)}$ unit. The chemical shift suggests that the $\mathrm{B}^{(3)}$ units are predominantly linked to other $\mathrm{B}^{(3)}$ or $\mathrm{B}^{(4)}$ units via $\mathrm{B}-\mathrm{O}-\mathrm{B}$ linkages. We find no evidence for $\mathrm{B}^{(3)}-\mathrm{O}-\mathrm{Si}$ linkages which would give rise to line shape components with lower chemical shifts, near 10-12 ppm. ${ }^{35}$ While the value of the asymmetry parameter appears rather large for $\mathrm{a} \mathrm{B}^{(3)}$ species, a line shape of this kind will also arise if there is a distribution of quadrupolar coupling constants and/or chemical shifts. Due to the underdetermined character of this fitting problem it is generally not possible to extract unique distribution functions of these parameters from such spectra (Table 3 ).

Thus, the high value of $\eta_{\mathrm{Q}}$ might be an artifact created by our fitting approach of using a singular value of $C_{\mathrm{Q}}$ when there is really a distribution present. Based on the spectra observed, as well as on charge balance considerations discussed further below, we attribute the trigonal borate species to uncharged $\mathrm{B}^{(3)}$ units $\left(\mathrm{BO}_{3 / 2}\right.$ groups) linked predominantly to other borate species within cyclic or oligomeric borate clusters. The formation of such species, which would tend to clog the micropores may explain the sudden drop in surface area in going from 10 to $15 \mathrm{~mol} \% \mathrm{~B}_{2} \mathrm{O}_{3}$.

To probe connectivity and spatial proximity of these boron species with phosphorus, ${ }^{11} \mathrm{~B}\left\{{ }^{31} \mathrm{P}\right\}$ REDOR experiments were 


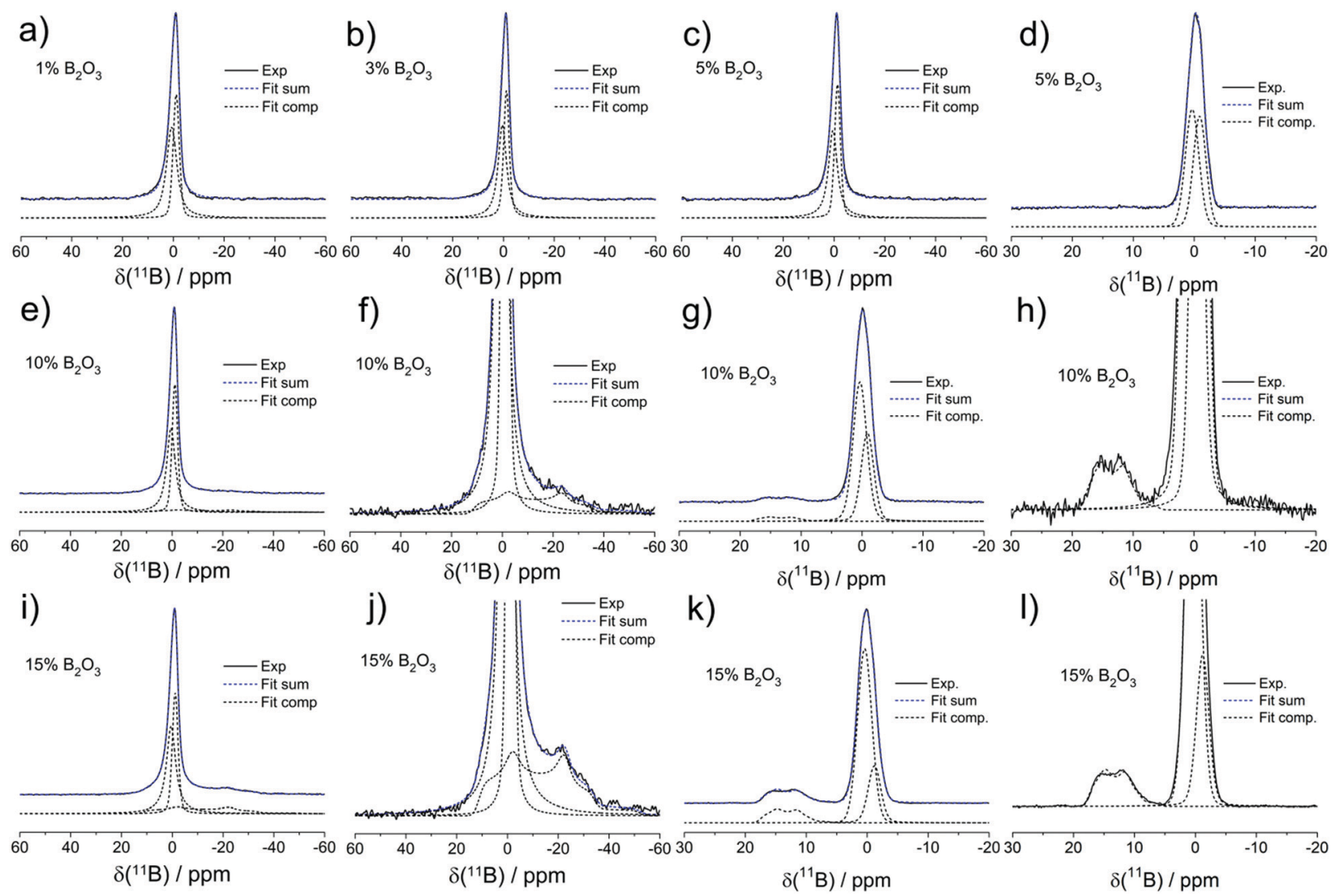

Fig. 5 Field-dependent experimental and simulated ${ }^{11} \mathrm{~B}$ MAS-NMR spectra of boron oxide modified MBGs with different $\mathrm{B}_{2} \mathrm{O}_{3}$ contents: (a) 1 mol\%, $5.64 \mathrm{~T}$; (b) 3 mol\%, $5.64 \mathrm{~T}$; (c) 5 mol\%, $5.64 \mathrm{~T}$; (d) 5 mol\%, $14.1 \mathrm{~T}$; (e) $10 \mathrm{~mol} \%, 5.64 \mathrm{~T}$; (f) $10 \mathrm{~mol} \%, 5.64 \mathrm{~T}$, vertically expanded; (g) $10 \mathrm{~mol} \% 14.1 \mathrm{~T}$; (h) $10 \mathrm{~mol} \% 14.1 \mathrm{~T}$, vertically expanded, (i) 15 mol\%, $5.64 \mathrm{~T}$, (j) $15 \mathrm{~mol} \%, 5.64 \mathrm{~T}$, vertically expanded, (k) 15 mol\%, $14.1 \mathrm{~T}$, (l) 15 mol\%, $14.1 \mathrm{~T}$, vertically expanded.

conducted on two representative glasses. The results are shown in Fig. 6 along with data for the model compound $\mathrm{BPO}_{4}$.

The $M_{2(\mathrm{~B}-\mathrm{P})}$ values extracted from these plots, using eqn (1), are very small for both tetrahedral boron $\left(0.05 \times 10^{6}\right.$ and $0.07 \times$ $10^{6} \mathrm{rad}^{2} \mathrm{~s}^{-2}$ for glasses with 15 and $5 \mathrm{~mol} \% \mathrm{~B}_{2} \mathrm{O}_{3}$, respectively) and trigonal boron $\left(0.06 \times 10^{6} \mathrm{rad}^{2} \mathrm{~s}^{-2}\right.$ for glass with $15 \mathrm{~mol} \%$ $\left.\mathrm{B}_{2} \mathrm{O}_{3}\right)$, compared to $\mathrm{BPO}_{4}\left(11.2 \times 10^{6} \mathrm{rad}^{2} \mathrm{~s}^{-2}\right)$. Considering that the $\mathrm{B} \cdots \mathrm{P}$ distances across a $\mathrm{B}-\mathrm{O}-\mathrm{P}$ linkage in the glasses are of similar magnitude as those in the crystalline model compound $\mathrm{BPO}_{4}(4 \mathrm{~B} \cdots \mathrm{P}$ distances at $277 \mathrm{pm})$ the result shows that the number of $\mathrm{B}-\mathrm{O}-\mathrm{P}$ linkages in the present glasses is negligible. Nevertheless, based on the observation of a non-zero REDOR effect (Fig. 6, bottom) we can conclude a spatial proximity between the boron and the phosphorus species, indicating that both components coexist within the same phase and are not separated in different phases.

Fig. 7 summarizes the results from ${ }^{31} \mathrm{P}$ MAS-NMR. Peak deconvolutions and assignments are summarized in Table 4. In the absence of boron, one dominant peak at $3.4 \pm 0.2 \mathrm{ppm}$ is observed, which can be assigned to the expected orthophosphate $\left(\mathrm{P}^{(0)}\right)$ species. In glasses having $\mathrm{B}_{2} \mathrm{O}_{3}$ contents $>5 \mathrm{~mol} \%$ a minor component near $-2.9 \mathrm{ppm}$ is observed, suggesting the formation of a $\mathrm{P}^{(1)}$ - type species. Here $n$, the superscript of the $\mathrm{P}^{(n)}$ notation, is the number of bridging oxygen atoms (rather than the number of $\mathrm{P}-\mathrm{O}-\mathrm{P}$ linkages that would be specified in the frequently used $\mathrm{Q}^{(n)}$ nomenclature). As the B content is increased, the feature near $-2.9 \mathrm{ppm}$ gradually becomes stronger, suggesting a systematic increase of the $\mathrm{P}^{(1)}$ species concentration with increasing $\mathrm{B}_{2} \mathrm{O}_{3}$ content. Both signals show minimal effects in ${ }^{31} \mathrm{P}\left\{{ }^{11} \mathrm{~B}\right\}$ REAPDOR experiments (data not shown), again confirming the absence of significant $\mathrm{P}-\mathrm{O}-\mathrm{B}$ connectivity.

Fig. S5 (ESI $\dagger$ ) shows ${ }^{1} \mathrm{H}$ MAS-NMR spectra, revealing a dominant broad line near $5.0 \mathrm{ppm}$ and two distinct sharp components near 1.0 and $3.4 \mathrm{ppm}$. While the signal near $5.0 \mathrm{ppm}$ shows the typical signature of water adsorbed in the internal pores, the $1.0 \mathrm{ppm}$ peak can be attributed to $\mathrm{Si}-\mathrm{OH}$ groups. The peak near $3.4 \mathrm{ppm}$ represents a distinct and welldefined hydrogen species, and could possibly be assigned to a Broensted site, a $\mathrm{HPO}_{4}{ }^{2-}$ species or an $\mathrm{OH}$ group linked to a $\mathrm{B}^{(4)}$ unit. The latter two possibilities could be ruled out by $\left.{ }^{1} \mathrm{H}_{\{}{ }^{31} \mathrm{P}\right\}$ REDOR and ${ }^{1} \mathrm{H}\left\{{ }^{11} \mathrm{~B}\right\}$ REAPDOR experiments, which showed no dipolar recoupling effects. While a definitive assignment of this signal is not possible at the moment, we note their undiminished presence in boron-free Al-containing MBG samples.

\section{Discussion and conclusions}

The results of the present study indicate that borate modification of mesoporous bioactive glasses can enhance their 
Table 3 (A) Deconvolution parameters used in the simulation of the ${ }^{11} \mathrm{~B}$ MAS-NMR spectra of $\mathrm{B}_{2} \mathrm{O}_{3}$ doped MBGs (5.7 T). (B) Deconvolution parameters used in the simulation of the ${ }^{11} \mathrm{~B}$ MAS-NMR spectra of $\mathrm{B}_{2} \mathrm{O}_{3}$ doped MBGs (14.1 T)

\begin{tabular}{|c|c|c|c|c|c|c|}
\hline $\mathrm{mol} \% \mathrm{~B}_{2} \mathrm{O}_{3}$ & Component & $\delta_{\text {iso }}^{\mathrm{cs}} / \mathrm{ppm} \pm 0.5 \mathrm{ppm}$ & $C_{\mathrm{Q}} / \mathrm{MHz} \pm 0.1 \mathrm{MHz}$ & $\eta_{\mathrm{Q}}$ & FWHM/ppm \pm 0.5 ppm & Area fractions $/ \% \pm 1 \%$ \\
\hline \multicolumn{7}{|l|}{ (A) } \\
\hline \multirow[t]{3}{*}{15} & 1 & 15.2 & 2.5 & 0.35 & & 18 \\
\hline & 2 & 0.5 & & & 4.4 & 49 \\
\hline & 3 & -1.2 & & & 2.7 & 33 \\
\hline \multirow[t]{3}{*}{10} & 1 & 15.4 & 2.6 & 0.35 & & 8 \\
\hline & 2 & 0.4 & & & 4.0 & 52 \\
\hline & 3 & -1.1 & & & 2.6 & 40 \\
\hline \multirow[t]{2}{*}{5.0} & 1 & 0.4 & & & 4.2 & 56 \\
\hline & 2 & -1.4 & & & 2.7 & 44 \\
\hline \multirow[t]{2}{*}{3.0} & 1 & 0.4 & & & 4.0 & 56 \\
\hline & 2 & -1.2 & & & 2.6 & 44 \\
\hline \multirow[t]{2}{*}{1.0} & 1 & 0.7 & & & 4.9 & 60 \\
\hline & 2 & -1.1 & & & 2.9 & 40 \\
\hline \multicolumn{7}{|l|}{ (B) } \\
\hline \multirow[t]{3}{*}{15} & 1 & 18.1 & 2.7 & 0.39 & & 12 \\
\hline & 2 & 0.4 & & & 4.7 & 67 \\
\hline & 3 & -1.2 & & & 2.4 & 21 \\
\hline \multirow[t]{3}{*}{10} & 1 & 18.5 & 2.7 & 0.37 & & 4 \\
\hline & 2 & 0.4 & & & 2.6 & 60 \\
\hline & 3 & -0.9 & & & 2.5 & 35 \\
\hline \multirow[t]{2}{*}{5.0} & 1 & 0.4 & & & 2.6 & 53 \\
\hline & 2 & -0.9 & & & 2.5 & 47 \\
\hline
\end{tabular}
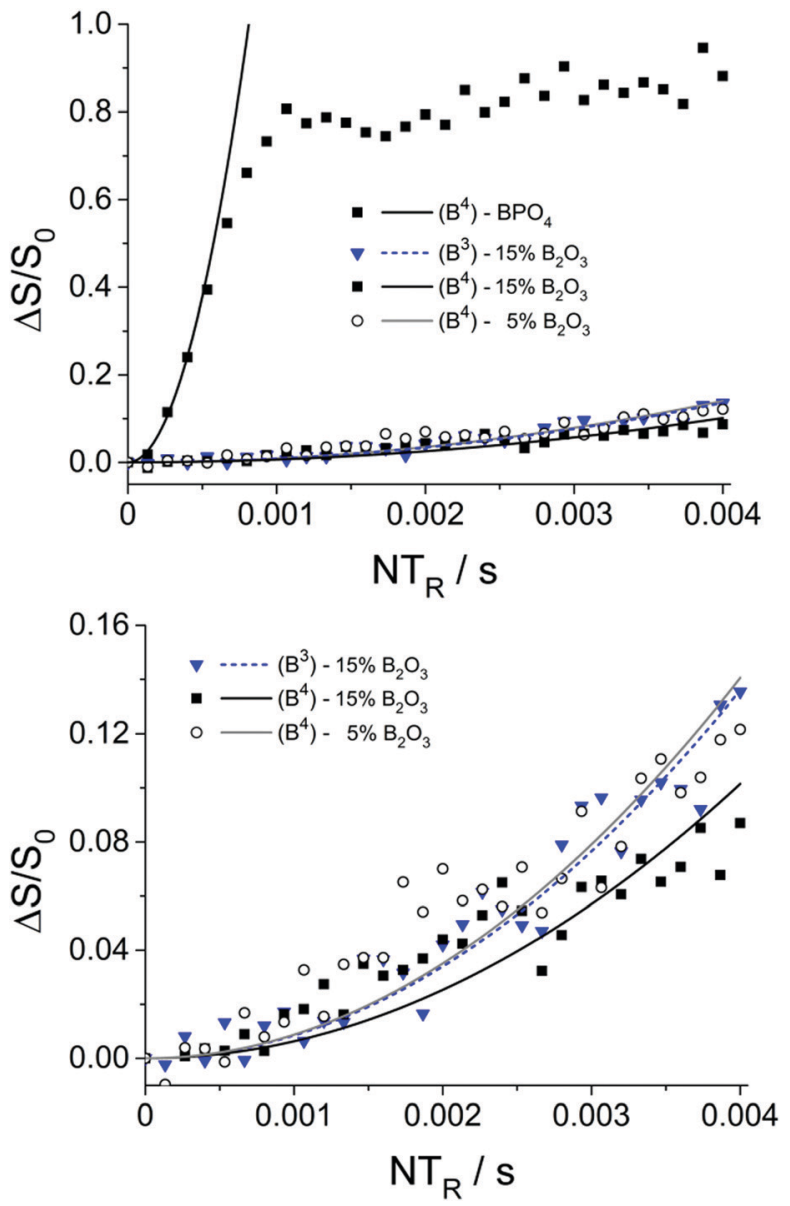

Fig. $6{ }^{11} \mathrm{~B}\left\{{ }^{31} \mathrm{P}\right\} R E D O R$ results and parabolic analyses (solid curves) of boron-doped MBGs containing 5 and 15 mol\% $\mathrm{B}_{2} \mathrm{O}_{3}$. Data for the model compound $\mathrm{BPO}_{4}$ are shown for comparison. Due to the limited signal-tonoise ratio of the data at longer evolution times, the expected oscillatory behavior of the REDOR curve of $\mathrm{BPO}_{4}{ }^{36}$ is not clearly evident in this data.
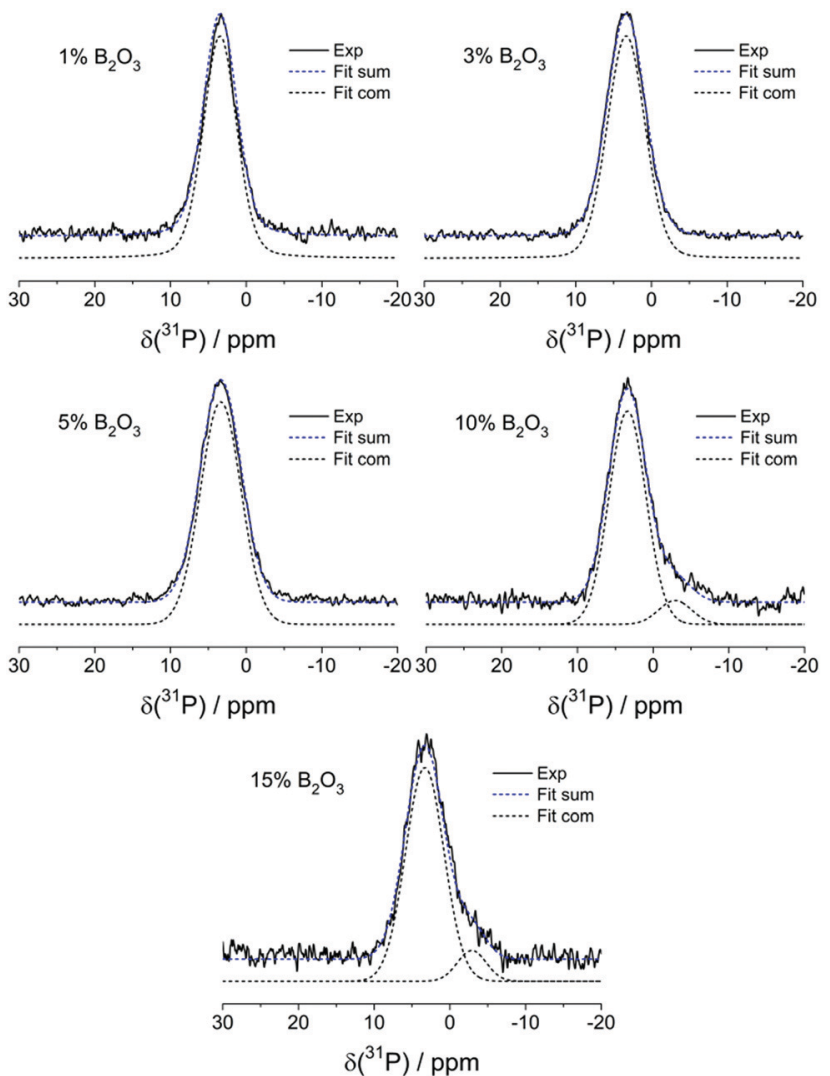

Fig. 7 Experimental and simulated ${ }^{31} \mathrm{P}$ MAS-NMR spectra of $\mathrm{B}_{2} \mathrm{O}_{3}$ doped MBGs.

mechanical properties as well as their bioactivity in SBF solutions.

TEM and BJH analysis confirm that, even at high concentrations, the incorporation of borates has no significant effect on the pore 
Table 4 Deconvolution parameters used in the simulation of the ${ }^{31} \mathrm{P}$ MAS-NMR spectra of $\mathrm{B}_{2} \mathrm{O}_{3}$ doped MBGs

\begin{tabular}{llclc}
\hline $\begin{array}{l}\text { mol\% } \\
\mathrm{B}_{2} \mathrm{O}_{3}\end{array}$ & Component & $\begin{array}{l}\delta_{\text {iso }}^{\text {cs }} / \mathrm{ppm} \\
\pm 0.5 \mathrm{ppm}\end{array}$ & $\begin{array}{l}\text { FWHM/ppm } \\
\pm 0.5 \mathrm{ppm}\end{array}$ & $\begin{array}{l}\text { Area fractions/\% } \\
\pm 2 \%\end{array}$ \\
\hline 15 & 1 & 3.3 & 6.0 & 90 \\
& 2 & -2.9 & 4.5 & 10 \\
10 & 1 & 3.4 & 5.8 & 91 \\
& 2 & -2.9 & 5.1 & 9 \\
5.0 & 1 & 3.4 & 6.3 & 100 \\
3.0 & 1 & 3.4 & 5.9 & 100 \\
1.0 & 1 & 3.5 & 5.2 & 100
\end{tabular}

ordering or on the average pore diameter. The observed gradual decrease in specific surface area with increasing boron concentration is thus attributable to a diminished contribution by micropores within the glass network, such as through pore blocking.

ICP results reveal a quick and quantitative boron release into the SFB solution in direct correlation between the boron release and the initial boron concentration in the glasses and confirm that the boron species are quickly and quantitatively released into the SBF solution. This suggests that the boron species are not incorporated within the glass network, but rather weakly bound on the interior surface of the mesopores, resulting in the aforementioned blocking of micropores. The presence of boron accelerates the release of Si from the silicate network. The increasing amounts of $\mathrm{Si}$ being released with higher boron concentrations may facilitate a collapse of the pore network and loss of internal surface area. This loss in porosity may restrict the re-uptake of $\mathrm{Ca}$ in the form of HCA. Consequently, there is a compromise between Si release/pore collapse and Ca release/uptake, which appears to be optimal at boron concentrations between $1 \%$ and $3 \%$.

The mechanical properties improve considerably with boron incorporation. Again, it appears that the samples with 1-3\% B offer the best results, i.e. a modulus (13-16 GPa) that is just slightly lower than that of cortical bone, and hardness (about $1 \mathrm{GPa}$ ), which is not too strong for bone transplant applications. ${ }^{34}$

The NMR results indicate that - contrary to the situation in 45S5 bioglasses - the phosphorus speciation in the present samples is significantly influenced by the $\mathrm{B}_{2} \mathrm{O}_{3}$ component. While at low boron content only $\mathrm{P}^{(0)}$ species can be detected, there is clear evidence for $\mathrm{P}^{(1)}$ species at higher borate contents. This can be explained by the fact that the anionic $\mathrm{B}^{(4)}$ units formed are competing with the phosphate anions for charge compensation by $\mathrm{Ca}^{2+}$ and possibly protonic species. Whether these $\mathrm{P}^{(1)}$ units are pyrophosphate groups or end groups linking to silica with $\mathrm{P}-\mathrm{O}-\mathrm{Si}$ linkages cannot be determined at the present stage. There is no clear evidence that the $\mathrm{B}^{(4)}$ units are integrated into the silica framework. Both, changes in ${ }^{11} \mathrm{~B}$ chemical shift and the appearance of $\mathrm{B}^{(3)}$ species at $\mathrm{B}_{2} \mathrm{O}_{3}$ contents $\geq 10 \mathrm{~mol} \%$, suggest the appearance of $\mathrm{B}^{(4)}-\mathrm{O}-\mathrm{B}^{(3)}$ linkages, which is consistent with previous results in the literature obtained on bioglasses. ${ }^{21,22}$ The phosphate species in bioactive glasses is predominantly of the orthophosphate $\left(\mathrm{P}^{(0)}\right)$ type, if the inventory of modifier cations is sufficient to balance the total charge of all of the anionic species present. ${ }^{14}$
Regarding this model (and not considering the presence of protonic species), the B-free glass of the present study was designed to be perfectly charge-balanced as the amount of $\mathrm{Ca}^{2+}$ ions (15 mol\%) present is sufficient to compensate the charge of the $5 \mathrm{~mol} \%$ of orthophosphate $\left(\mathrm{PO}_{4}{ }^{3-}\right)$ ions. For borate containing glasses, the total concentration $A$ of accumulated negative (anionic) charges is given by:

$A=10 \times\left[3 \times f\left(\mathrm{P}^{(0)}\right)+2 \times f\left(\mathrm{P}^{(1)}\right)\right]+2 x \times f\left(\mathrm{~B}^{(4)}\right) \mathrm{mol} \%$

where $x$ specifies the $\mathrm{B}_{2} \mathrm{O}_{3}$ content (in mol\%) and the $f$ values denote the fractional areas of the two types of phosphate species and of the four-coordinate boron species determined from the ${ }^{31} \mathrm{P}$ and the ${ }^{11} \mathrm{~B}$ spectra, respectively. For charge neutrality of the entire sample, $A$ has to be equal to the sum of positive cationic charges contributed by $\mathrm{Ca}^{2+}$ and protons,

$$
C=2 \times 15 \mathrm{~mol} \%+z
$$

Here $z$ denotes concentration of protons, which cannot be quantified reliably in the current set of experiments. The situation in the present MBGs is similar to that observed in the boron-containing melt-quenched bioglasses studied by Yu and Edén, ${ }^{21,22}$ where the addition of boron was also shown to lead to an overall increased degree of network polymerization. In those glasses, however, replacement of silica by boron oxide produces a systematic increase in the number of $\mathrm{Si}-\mathrm{O}-\mathrm{Si}$ linkages, while the phosphate inventory is left unchanged. In contrast, in the MBGs of the present study, the silicate species is already fully polymerized (aside from the presence of some silanol groups), such that addition of boron has a direct influence on the phosphate speciation. The effect appears to be much smaller, however, than expected based on eqn (2). We must therefore conclude, that protonic species, created by the calcination process for template removal, must participate in the charge balancing mechanism.

Finally, the structural effects of boron-doping of MBGs are distinctly different from those observed for aluminum doping. ${ }^{23}$ In the latter materials, there is definitive evidence for a significant amount of Al-O-P linkages associated with six-coordinated $\mathrm{Al}$ species; furthermore, the anionic $\mathrm{Al}^{(4)}$ species are integrated in the silicate network, resulting in strong Al-O-Si linkages charge compensated by $\mathrm{Ca}^{2+}$ ions. While both of these structural features have the desired effect to increase the mechanical strength of these materials, they also impede the disintegration of the silicate network, as well as the release of phosphate and calcium, leading to significantly decreased bioactivities. In contrast, borate incorporation results in the desired combination of increased mechanical stability and bioactivity. This result is attributed to (1) a borate distribution dominantly at the pore surface, thus maintaining the highly ordered mesoporous structure of the material; (2) the absence of B-O-P connectivity as indicated by the REDOR results; (3) a weaker Coulombic interaction between the tetrahedral $\mathrm{BO}_{4}$ units and the charge-compensating $\mathrm{Ca}^{2+}$ ions; (4) at high borate contents the formation of hydrolytically unstable $\mathrm{B}-\mathrm{O}-\mathrm{B}$ linkages involving $\mathrm{B}^{(3)}$ units. The concomitant reduction in surface area at these high borate concentrations can be 
understood in terms of the formation of polymeric or cyclic borate ring structures containing $\mathrm{B}^{(3)}$ and $\mathrm{B}^{(4)}$ units, which clog the mesopores and/or their openings. Overall, the results of the present study suggest that borate-modified MBGs at the level of 1-3 mol\% $\mathrm{B}_{2} \mathrm{O}_{3}$ are a promising class of bioactive materials with improved mechanical properties, which warrant further study. In view of the remarkably different structural modification mechanisms observed in the $\mathrm{B}_{2} \mathrm{O}_{3}$ and $\mathrm{Al}_{2} \mathrm{O}_{3}$ containing systems it will be of interest to study the competition of both processes in co-doped systems. These studies are currently being pursued in our laboratories.

\section{Conflicts of interest}

There are no conflicts to declare.

\section{Acknowledgements}

TEM analysis was carried out using the facilities at the University Service Centre for Transmission Electron Microscopy, TU Wien, Austria. H. E. would like to acknowledge the Brazilian funding agencies FAPESP (CEPID Project 2013/07793-6) and CNPq. H. B. also thanks for support from the Deutsche Forschungsgemeinschaft.

\section{References}

1 L. L. Hench, J. Mater. Sci.: Mater. Med., 2006, 17, 967-978.

2 L. L. Hench, R. J. Splinter, W. C. Allen and T. K. Greenlee, J. Biomed. Mater. Res., 1971, 5, 117-141.

3 W. P. Cao and L. L. Hench, Ceram. Int., 1996, 22, 493-507.

4 R. Li, A. E. Clark and L. L. Hench, J. Appl. Biomater., 1991, 2, 231-239.

5 X. Yan, C. Yu, X. Zhou, J. Tang and D. Zhao, Angew. Chem., Int. Ed., 2004, 43, 5980-5984.

6 C. J. Brinker, Y. Lu, A. Sellinger and H. Fan, Adv. Mater., 1999, 11, 579-585.

7 I. Izquierdo-Barba and M. Vallet-Regi, Solid State Sci., 2011, 13, 773-783.

8 M. Cicuéndez, M. T. Portolés, I. Izquierdo-Barba and M. Vallet-Regí, Chem. Mater., 2012, 24, 1100-1106.

9 H. S. Yun, S. E. Kim and Y. T. Hyeon, Mater. Lett., 2007, 61, 4569-4572.

10 A. López-Noriega, D. Arcos and M. Vallet-Regí, Chem. - Eur. J., 2010, 16, 10879-10886.

11 C. T. Wu, Y. F. Zhang, Y. F. Zhu, T. Friis and Y. Xiao, Biomaterials, 2010, 31, 3429-3438.
12 C. Kohlhauser, C. Hellmich, C. Vitale-Brovarone, A. R. Boccaccini, A. Rota and J. Eberhardsteiner, Strain, 2009, 45, 34-44.

13 N. Sharmin, A. J. Parsons, C. D. Rudd and I. Ahmed, J. Biomater. Appl., 2014, 29, 639-653.

14 P. Balasubramanian, T. Buttner, V. M. Pacheco and A. R. Boccaccini, J. Eur. Ceram. Soc., 2018, 38, 855-869.

15 C. T. Wu and J. Chang, J. Controlled Release, 2014, 193, 282-295.

16 R. Patricia, R.-N. Aleixandre and S.-S. Manuel, Tissue Eng., Part A, 2015, 21, 2662-2672.

17 O. Sych, O. Gunduz, N. Pinchuk, G. E. Stan and F. N. Oktar, J. Aust. Ceram. Soc., 2016, 52, 103-110.

18 F. Baino, M. Marshall, N. Kirk and C. Vitale-Brovarone, Ceram. Int., 2016, 42, 1482-1491.

19 H. B. Pan, X. L. Zhao, X. Zhang, K. B. Zhang, L. C. Li, Z. Y. Li, W. M. Lam, W. W. Lu, D. P. Wang, W. H. Huang, K. L. Lin and J. Chang, J. R. Soc., Interface, 2010, 7, 1025-1031.

20 H. Eckert, J. Sol-Gel Sci. Technol., 2018, 88, 263-295.

21 Y. Yu and M. Edén, RSC Adv., 2016, 6, 101288-101303.

22 Y. Yu, B. Stevensson and M. Edén, J. Phys. Chem. B, 2017, 121, 9737-9752.

23 S. Melchers, T. Uesbeck, O. Winter, H. Eckert and D. Eder, Chem. Mater., 2016, 28, 3254-3264.

24 M. Thommes, K. Kaneko, A. V. Neimark, J. P. Olivier, F. Rodriguez-Reinoso, J. Rouquerol and K. S. W. Sing, Pure Appl. Chem., 2015, 87, 1051-1069.

25 G. M. Pharr and W. C. Oliver, MRS Bull., 1992, 17, 28-33.

26 T. Kokubo and H. Takadama, Biomaterials, 2006, 27, 2907-2915.

27 D. Massiot, F. Fayon, M. Capron, I. King, S. Le Calvé, B. Alonso, J.-O. Durand, B. Bujoli, Z. Gan and G. Hoatson, Magn. Reson. Chem., 2002, 40, 70-76.

28 T. Gullion and J. Schaefer, J. Magn. Reson., 1989, 81, 196-200.

29 M. Bertmer and H. Eckert, Solid State Nucl. Magn. Reson., 1999, 15, 139-152.

30 J. H. Van Vleck, Phys. Rev., 1948, 74, 1168-1183.

31 G. Constantinides and F. J. Ulm, J. Mech. Phys. Solids, 2007, 55, 64-90.

32 W. J. Drugan and J. R. Willis, J. Mech. Phys. Solids, 1996, 44, 497-524.

33 M. Miller, C. Bobko, M. Vandamme and F.-J. Ulm, Cem. Concr. Res., 2008, 38, 467-476.

34 V. A. Koleganova, S. M. Bernier, S. J. Dixon and A. S. Rizkalla, J. Biomed. Mater. Res., Part A, 2006, 77A, 572-579.

35 D. Möncke, D. Ehrt, H. Eckert and V. Mertens, Phys. Chem. Glasses, 2003, 44, 113-116.

36 H. Eckert, Bunsenmagazin, 2008, 5, 159-179. 